\title{
Sulfotransferase 1A1
}

National Cancer Institute

\section{Source}

National Cancer Institute. Sulfotransferase 1A1. NCI Thesaurus. Code C107443.

Sulfotransferase 1A1 (295 aa, 34 kDa) is encoded by the human SULT1A1 gene. This protein is involved in the sulfate conjug ation of catecholamines, phenolic drugs and neurotransmitters. 